\title{
DETERMINATION OF NINE COMPONENTS IN BAYER LIQUORS BY HIGH PERFORMANCE ION CHROMATOGRAPHY WITH CONDUCTIVITY DETECTOR
}

\author{
JIAN BO XIAO \\ College of Chemistry and Chemical Engineering, Central South University, China
}

\begin{abstract}
A High Performance Ion Chromatographic (HPIC) method for the determination of nine components in Bayer liquors was reported. Formic, acetic, propionic, oxalic, succinic, glutaric anion, $\mathrm{F}^{-}, \mathrm{Cl}^{-}$, and $\mathrm{SO}_{4}{ }^{2-}$ were separated and determined by High Performance Ion Chromatography with conductivity detector. The analytes were removed from Bayer liquor by using an ion-exchange resin column. The chromatographic separation was achieved with only one IonPac AS11-HC column thermostated at $30^{\circ} \mathrm{C}$. The precision results showed that the repeatability and reproducibility were $<2.94$ and $<1.37 \%$, respectively. The accuracy of the method was assessed by the recoveries ranging from 86.3 to $105.6 \%$. Under optimum conditions the detection limits ranged from 0.008 to $0.053 \mathrm{mg} / \mathrm{l}$.
\end{abstract}

Keywords: Bayer liquors; High Performance Ion Chromatography; anions; determination

\section{INTRODUCTION}

The Bayer process can be summarized as the digestion of bauxite with caustic liquor and the subsequent precipitation of hydrated alumina [1]. Most bauxite contains organic matter in various amounts. The major source of organic matter introduced within the Bayer liquor comes from the bauxite in the form of humic substances. During the digestion, the organic matter is dissolved, degraded and oxidized with the results that the liquors darken, and notable amounts of oxalate and carbonate are formed.

Due to the acidic nature of the humic substances, more than $50 \%$ of the organic matter contained in the bauxite is extracted into the liquor. The principal degradation products are sodium oxalate and sodium carbonate Depending upon the digestion conditions, typically $5-10 \%$ of the organic carbon is converted to sodium oxalate [2].

The process is cyclical and therefore concomitant impurities present in the raw materials or reagents may accumulate unless periodically removed [3, 4]. From an analytical chemistry perspective, Bayer liquor is a challenging matrix consisting of alumina, sodium hydroxide, sodium carbonate, sodium chloride, sodium sulphate, sodium oxalate as well as unknown organic acid anions all at varying concentrations [5-7]. The rapid and reliable determination of organic acids in Bayer liquor is of significant industrial importance because their presence is implicated in the formation of small particle size hydrated alumina [8].

A variety of techniques have been utilized for the identification and determination of sodium oxalate and humic substances in Bayer liquors; these have included titrimetry [9], ion chromatography [7, 10-11], capillary electrophoresis [7,11-15], flow injection analysis [16], high performance liquid chromatograph [17-21] and gas chromatography [22-24]. Any reports analyzing the humic acids by IC had been restricted to only oxalic acid analysis [10-11]. But the quantitative determination was not performed because the separation is inadequate. Oxalate was the main organic component in Bayer liquor. In many factories the oxalate was determined by titration with standard potassium permanganate solution. This method often resulted in low precision and accuracy. Furthermore, it takes much time and agents. The analysis of organic acids in Bayer liquors with IC systems is a difficult task due to high ionic strength and $\mathrm{pH}$. Our particular interest concerns the development of a simple HPIC procedure for the determination of organic and inorganic anions levels in Bayer liquors. The method was successfully applied to analysis of Bayer liquor samples with high recoveries and precision.

\section{EXPERIMENTAL}

\subsection{Materials and methods}

\subsubsection{Chemicals and standards}

Analytical standard-grade formic, acetic, propionic, oxalic, succinic, glutaric acid, and sodium fluoride, sodium chloride, potassium sulfate were obtained from Sigma (St. Louis, MO, USA). Stock standard solutions were prepared by dissolution of acids in Milli-Q water; they were stored at $4{ }^{\circ} \mathrm{C}$ for 1 month. The Milli-Q water was purified by passage through a Compact Milli-RO and Milli-Q water system from Millipore (Milford, MA, USA) Working standard solutions were prepared daily by dilution with Milli-Q water.
Potassium dihydrogenphosphate, sodium hydrogen carbonate, orthophosphoric and hydrochloric acid were analytical-reagent grade and supplied by Shanghai (Shanghai, China).

The samples were filtered through cellulose membrane filters Whatman $(0.45 \mu \mathrm{m}$, Whatman, Clifton, NJ, USA). The eluent was filtered with membrane filters Phenomenex (0.45 $\mu \mathrm{m}, \mathrm{AFO}-0504, \mathrm{CA}, \mathrm{USA})$.

\subsubsection{Apparatus}

High Performance Ion Chromatographic analyses were carried out using a DIONEX Ion Chromatograph (USA) equipped with a DIONEX EG50 on-line degasser, a DIONEX EG50 GP50pump, and a ASRS-ULTRA $\square$ 4-mm detection system (DIONEX). The detector signals were recorded on a chromatography data system Chromeleon 6.60. The column was an IonPac AS11-HC column $(250 \times 4.6 \mathrm{~mm}$ I.D., particle size $5 \mu \mathrm{m}$, Hanbon Science \&Technology Co., Ltd). SPE column was an OnGuard H column (DIONEX). A PHS-3C pH meter (Shanghai, China) was also used.

\subsubsection{Sample preparation}

A $10 \mathrm{ml}$ amount of Bayer liquor was diluted in $1000 \mathrm{ml}$ of Milli-Q water. The $\mathrm{pH}$ was adjusted to approximately $7.50 \mathrm{using} 8 \mathrm{~mol} / 1 \mathrm{HCl}$ and the mixture was stirred for $15 \mathrm{~min}$ using a magnetic stirrer. The SPE procedure involved an ion-exchange cartridge $(100 \times 4.6 \mathrm{mmI}$.D., particle size $40 \mu \mathrm{m}$, Hanbon Science \&Technology Co., Ltd), which was activated with $10 \mathrm{ml}$ of sodium hydroxide solution $0.1 \mathrm{~mol} / 1$ (percolation rate $3 \mathrm{ml} / \mathrm{min}$ ). A $100-\mathrm{ml}$ volume of solution diluted was passed through at a flow-rate of $0.5 \mathrm{ml} / \mathrm{min}$. The cartridge was washed with $100 \mathrm{ml}$ of water $(3.0 \mathrm{ml} / \mathrm{min})$ and organic acids and inorganic anions were eluted with $50 \mathrm{ml}$ of hydrochloric acid $0.1 \mathrm{~mol} / 1(1.0 \mathrm{ml} / \mathrm{min})$. This solution was injected directly in the chromatograph after filtered.

2.1.4. Chromatographic conditions

The mobile phases used were water and potassium hydroxide. All procedures were carried out using a gradient elution program (Table 1). The flow-rate was $1.20 \mathrm{ml} / \mathrm{min}$. The column was thermostated at $30^{\circ} \mathrm{C}$. Injection volume was $25 \mu \mathrm{l}$ and all standards and Bayer liquor samples were filtered through a $0.45-\mu \mathrm{m}$ membrane.

Table 1. Gradient profile used in Ion Chromatography

\begin{tabular}{|c|c|}
\hline $\mathrm{t} / \mathrm{min}$ & $\mathrm{c}(\mathrm{KOH}) / \mathrm{mmol} / 1$ \\
\hline 0.0 & 1.0 \\
\hline 12.0 & 1.0 \\
\hline 30.0 & 28.0 \\
\hline 33.0 & 28.0 \\
\hline 33.1 & 1.0 \\
\hline
\end{tabular}

\subsubsection{Calibration standards}

The individual standards were dissolved in methanol and injected to determine individual retention times. Stock solutions of $100 \mu \mathrm{g} / \mathrm{ml}$ of all organic acids and inorganic anions were prepared by dissolving pure standards in methanol. The stock solutions and the six diluted standards were injected for linearity range and detection limit tests. 


\section{RESULTS AND DISCUSSION}

\subsection{Optimization studies of the chromatographic condition}

\subsubsection{Mobile phase}

Solutions of acid or base, recommended in the literature [25-28] for determination of anions using High Performance Ion Chromatography, were tested. Solution of potassium hydroxide was selected because mobile phase consisting of acid produced interferences. Several concentrations of potassium hydroxide were tested and finally a gradient elution program was selected (Table 1).

\subsubsection{Column temperature}

The column was thermo stated at several different temperatures. The best results were obtained at a temperature of $30^{\circ} \mathrm{C}$.

\subsubsection{Flow rate of mobile phase}

Several mobile phase flow-rates $(0.5-1.5 \mathrm{ml} / \mathrm{min})$ were tested and finally a flow-rate of $1.20 \mathrm{ml} / \mathrm{min}$ was selected.

\subsection{Chromatographic separation}

Fig. 1 showed a chromatogram of these standard solutions. The chromatogram of sample is showed in Figs. 2. In this study gradient profiles were sufficient to separate six organic acids and three inorganic anions in a short time. Jackson compared the ion chromatography (IC) and capillary electrophoresis (CE) for determination of oxalate in Bayer liquors [11]. The eluent was complicated, which consisted of $1.6 \mathrm{mmol} / 1$ sodium tetraborate, $7.3 \mathrm{mmol} / 1$ boric acid, $1.6 \mathrm{mmol} / 1$ sodium gluconate, $5 \mathrm{~g} / 1$ glycerin, $120 \mathrm{ml} / 1$ acetonitrile and $20 \mathrm{ml} / 1 \mathrm{l}$-butanol at $\mathrm{pH} 8.5$. Only oxalate, $\mathrm{Cl}^{-}$, and $\mathrm{SO}_{4}{ }_{4}^{-2}$ were analyzed. Xiao et al separated and determined six organic acids in Bayer liquors by RP-HPLC [21]. Oxalic, tartaric, acetic, succinic, glutaric and butene dicarboxylic acids were identified and quantified [21]. But tartaric and butene dicarboxylic acids were not found by High Performance Ion Chromatographic (HPIC) method. So the tailed peak between peaks 7 and 8 may be some components that can not be separated by HPIC method.

Our particular interest concerns the development of a simple HPIC procedure for the determination of organic acids and inorganic anions levels in Bayer liquors. It is the first time that ion chromatography has been used to determine five organic acids (expect for oxalic acid) in Bayer liquor samples. A variety of techniques have been utilized for the determination of sodium oxalate in Bayer liquors. In contrast to these methods, the present method is simple, rapid and requires only extraction steps. A good separation can be achieved in a short separation time of $33 \mathrm{~min}$.

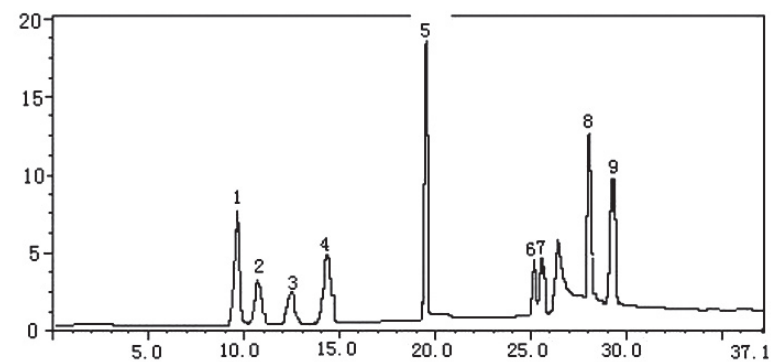

Fig. 1 IC-CD chromatogram of the standards.

1. $\mathrm{F}^{-}, 2$. acetic, 3 propionic, 4.formic, 5. $\mathrm{Cl}$, 6.glutaric, 7.succinic, 8. $\mathrm{SO}_{4}^{2-}$, 9.oxalic

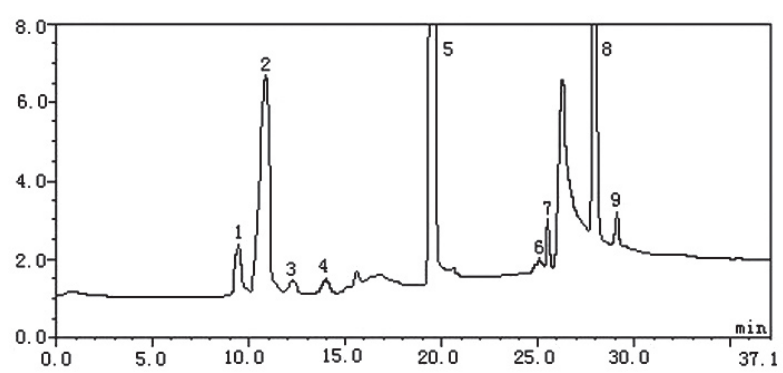

Fig. 2. IC-CD chromatogram of sample
1. $\mathrm{F}^{-}, 2$. acetic, 3 propionic, 4.formic, 5. $\mathrm{Cl}^{-}$, 6.glutaric, 7.succinic, 8. $\mathrm{SO}_{4}^{2-}$, 9.oxalic

The levels of oxalic acid found in Bayer liquors by IC are in agreement with the volumetric analysis (VA): potassium permanganate titration. Deviation was $1.2 \%-2.4 \%$. The oxalate levels determined by VA are always higher than the result of IC. We conclude that potassium permanganate is a versatile and powerful oxidant that can be used to determine many substances by direct or indirect titration. Some other compounds in Bayer liquors reacted with potassium permanganate.

\subsection{Detection and quantification limits}

Retention times of organic acids and inorganic anions analyzed were shown in the Table 2. The detection limit was calculated as $s_{\mathrm{b}}+6 s$, where $s_{\mathrm{b}}$ is the average signal of ten blank injections and $s$ the standard deviation. The quantification limit was calculated as $s_{\mathrm{b}}+10 s$, where $s_{\mathrm{b}}$ is the average signal of ten blank injections and $s$ the standard deviation. Table 3 shows detection and quantification limits of organic acids and inorganic anions analyzed. The detection limits ranged from $0.008 \mathrm{mg} / 1$ for $\mathrm{F}^{-}$to $0.053 \mathrm{mg} / 1$ for $\mathrm{Cl}^{-}$and the quantification limits ranged from $0.005 \mathrm{mg} / \mathrm{l}$ for $\mathrm{F}^{-}$to $1.00 \mathrm{mg} / \mathrm{l}$ for acetic acid.

Table 2. Retention times of nine anions analyzed.

\begin{tabular}{|c|c|}
\hline Components & Retention time (min) \pm SD \\
\hline $\mathrm{F}^{-}$ & $9.19 \pm 0.03$ \\
\hline acetic & $10.74 \pm 0.06$ \\
\hline propionic & $12.06 \pm 0.05$ \\
\hline formic & $13.74 \pm 0.04$ \\
\hline $\mathrm{Cl}^{-}$ & $19.55 \pm 0.05$ \\
\hline glutaric $^{-}$ & $25.13 \pm 0.04$ \\
\hline succinic & $25.53 \pm 0.02$ \\
\hline $\mathrm{SO}_{4}^{2-}$ & $27.92 \pm 0.03$ \\
\hline oxalic & $29.11 \pm 0.03$ \\
\hline
\end{tabular}

Table 3. Detection and quantification limits of nine anions analyzed.

\begin{tabular}{|c|c|c|}
\hline Components & $\begin{array}{c}\text { Detection limit } \\
(\mathrm{mg} / \mathrm{l})\end{array}$ & $\begin{array}{c}\text { Quantification limit } \\
(\mathrm{mg} / \mathrm{l})\end{array}$ \\
\hline $\mathrm{F}^{-}$ & 0.008 & 0.05 \\
\hline acetic & 0.013 & 1.00 \\
\hline propionic & 0.025 & 0.25 \\
\hline formic & 0.041 & 0.50 \\
\hline $\mathrm{Cl}^{-}$ & 0.053 & 1.00 \\
\hline glutaric & 0.032 & 0.20 \\
\hline succinic & 0.023 & 0.25 \\
\hline $\mathrm{SO}_{4}^{2-}$ & 0.037 & 0.50 \\
\hline oxalic $^{2-}$ & 0.019 & 0.20 \\
\hline
\end{tabular}

\subsection{Calibration curves}

Calibration curves were determined for seven different concentrations of a mixture of organic acids and inorganic anions standard solutions. Each calibration sample was injected in triplicate. Calibration graphs for each compound were obtained by plotting concentration against peak area and applying the least squares method. Table 4 lists the parameters and correlation coefficients of the calibration plots. Each plot was linear over certain interval from the detection limit to at least $10 \mu \mathrm{g} / \mathrm{ml}$ for all organic acids and inorganic anions. The peak areas $(y)$ and the theoretical concentrations of the calibration standards $(x)$ were fit to the $1 n$-quadratic function using the least squares regression in Microsoft Excel. The results of the regression analysis were then used to back-calculate the concentration results from the peak area data, and the back-calculated concentrations and appropriate summary statistics [mean, standard deviation (SD), and percent relative standard deviation (RSD)] were calculated and presented in tabular form. 
Table 4. Parameters and correlation coefficients $(r)$ of calibration plots for nine anions analyzed

\begin{tabular}{|c|c|c|c|}
\hline Components & $a$ & $b$ & $r$ \\
\hline $\mathrm{F}^{-}$ & 0.1850 & -0.0010 & 0.9993 \\
\hline acetic & 0.0332 & 0.0156 & 0.9995 \\
\hline propionic & 0.0363 & 0.0029 & 0.9991 \\
\hline formic & 0.0945 & -0.0067 & 0.9996 \\
\hline $\mathrm{Cl}^{-}$ & 0.1319 & -0.0085 & 0.9999 \\
\hline glutaric & 0.0283 & 0.0004 & 0.9998 \\
\hline succinic & 0.0328 & 0.0025 & 0.9999 \\
\hline $\mathrm{SO}_{4}^{2-}$ & 0.0955 & 0.0156 & 0.9999 \\
\hline oxalic $^{2-}$ & 0.0800 & 0.0004 & 0.9999 \\
\hline
\end{tabular}

Calibration plots are expressed as regression lines $(y=a x+b)$, where $y$ is the peak area and $x$ is the amount of acid in $\mathrm{mg} / \mathrm{L}$ Bayer liquor. The calibration test was repeated three times.

\subsection{Precision}

The precision study was comprised of repeatability and reproducibility studies. These were developed in three different Bayer liquors which contained low, medium and high organic acids and inorganic anions levels. The repeatability was established by injecting the Bayer liquor samples five times. The reproducibility was determined by analyzing each sample of Bayer liquors on 3 different days over about 1 month. The repeatability and the reproducibility are $<2.94 \%$ and $<1.37 \%$ (Table 5 ), respectively. These results indicate that the present method can be used for quantitative analyses of these nine anions in Bayer liquors.

Table 5. Repeatability and reproducibility of method

\begin{tabular}{|c|c|c|c|c|c|c|}
\hline Components & \multicolumn{3}{|c|}{ Repeatability (\%) } & \multicolumn{3}{c|}{ Reproducibility (\%) } \\
\hline $\mathrm{F}^{-}$ & 1.06 & 1.53 & 1.89 & 0.31 & 0.57 & 0.89 \\
\hline acetic & 0.87 & 1.24 & 1.97 & 1.02 & 0.79 & 1.27 \\
\hline propionic & 0.99 & 0.80 & 1.35 & 1.37 & 1.21 & 1.14 \\
\hline formic & 1.69 & 1.42 & 2.85 & 0.86 & 0.51 & 0.29 \\
\hline $\mathrm{Cl}^{-}$ & 2.64 & 2.94 & 2.01 & 0.34 & 0.78 & 0.45 \\
\hline glutaric & 1.93 & 2.21 & 2.74 & 0.84 & 0.93 & 1.28 \\
\hline succinic & 2.38 & 2.15 & 1.93 & 0.78 & 0.61 & 1.02 \\
\hline $\mathrm{SO}_{4}{ }^{2-}$ & 1.86 & 1.49 & 2.61 & 1.24 & 1.07 & 1.31 \\
\hline oxalic & 0.61 & 0.92 & 1.05 & 0.39 & 0.75 & 1.18 \\
\hline
\end{tabular}

\subsection{Recovery}

To establish the accuracy of the method, this procedure was also performed on a mixture of organic acids and inorganic anions added to Bayer liquors. Table 6 shows the recoveries of these anions after applying the extraction procedure. It is not possible to compare to our results those of other workers because it is the first time that this study has been carried out to determine these nine components in Bayer liquors by Ion Chromatography.
Table 6. Recovery of nine anions added to sample after the extraction procedure

\begin{tabular}{|c|c|c|c|}
\hline Components & Sample $/(\mathrm{g} / \mathrm{L})$ & Recovery $(\%) \pm \mathrm{SD}$ & $\mathrm{RSD}(\%)$ \\
\hline $\mathrm{F}^{-}$ & 0.132 & $95.3 \pm 3.2$ & 2.3 \\
\hline acetic & 4.726 & $102.7 \pm 2.1$ & 3.4 \\
\hline propionic & 0.202 & $86.3 \pm 3.1$ & 2.9 \\
\hline formic & 0.173 & $103.2 \pm 3.8$ & 2.5 \\
\hline $\mathrm{Cl}^{-}$ & 11.05 & $96.6 \pm 1.6$ & 1.9 \\
\hline glutaric & 0.070 & $105.6 \pm 4.7$ & 1.4 \\
\hline succinic & 0.445 & $89.7 \pm 2.5$ & 3.6 \\
\hline $\mathrm{SO}_{4}{ }^{2-}$ & 2.286 & $92.5 \pm 3.4$ & 4.9 \\
\hline oxalic & 0.160 & $94.6 \pm 1.9$ & 2.1 \\
\hline
\end{tabular}

\subsection{Nine nions contents in Bayer liquors analyzed}

The organic acids and inorganic anions contents of sample were shown in Table 6. $\mathrm{Cl}^{-}$and $\mathrm{SO}_{4}{ }^{2-}$ concentration were very high in sample. Six organic acids (formic, acetic, propionic, oxalic, succinic, glutaric acid) and three inorganic anions $\left(\mathrm{F}^{-}, \mathrm{Cl}^{-}\right.$, and $\left.\mathrm{SO}_{4}^{2-}\right)$ were separated and identified by the present ion chromatographic method.

\section{CONCLUSION}

The analysis of organic acids and inorganic anions in Bayer liquors with HPIC systems is a difficult task due to high ionic strength and $\mathrm{pH}$. The present method allows the quantification of formic, acetic, propionic, oxalic, succinic, glutaric acid, $\mathrm{F}^{-}, \mathrm{Cl}^{-}$, and $\mathrm{SO}_{4}^{2-}$ in Bayer liquors. The present method has the advantage of measuring organic acid in a single run, thus simplifying the analytical procedure.

\section{REFERENCES}

1. Pearson T.G. (1955). The chemical background of the aluminium industry, Monograph No. 5, Royal Institute of Chemistry, London, UK, 137-143,

2. Lever G.; (1983), Travaux, 13, 335-347.

3. Power G.P. (1991). Proceedings of the Extractive Metallurgy Conference, Perth, Australia,

4. Hind A.R., Bhargava S.K., Nunes M.D., Grocott S.C.; (1997), Chem. Aust., 64, 36.

5. Bouzat G., Philipponneau G.; (1991), Light Metals, 97-102.

6. Lectard A., Nicolas F.; (1983), Travaux, 133, 45.

7. Grocott S.C., Jefferies L.P., Bowser T., Carnevale J., Jackson P.E.;(1992), J. Chromatogr., 602, 257.

8. PowerG.P.,Tichbon W.(1990).Proceedings ofthe2ndInternationalAlumina Quality Workshop, Perth, Australia,

9. Vogel A.R.(1986). Textbook of Quantitative Inorganic Analysis, Longman, Harlow

10. Jackson P.E.; (1995), J. Chromatogr. A, 693, 155-161.

11. Bowser T., Grocott S.C.; (1990). Proceedings of the $2^{\text {nd }}$ International Alumina Quality Workshop, Perth, Australia,

12. Jackson P.E.; (1993), Chem. Aust., 60, 165.

13. Haddad P.R., Harakuwe A.H., Buchberger W.; (1995), J. Chromatogr. A, 706, 571-578.

14. Jackson P.E.; (1996), J. Chromatogr. A, 739, 399-403.

15. Chovancek M., Choo P., Macka M.; (2004), Electrophoresis, 25, 437443.

16. Barnett N.W., Lewis S.W., Purcell S.D., Jones P.; (2002), Anal Chim Acta, 458, 291-296.

17. Whelan T.J., Shalliker R.A., McIntyre C., Wilson M.A.; (2005), Ind. Eng. Chem. Res., 44, 3229-3237.

18. Whelan T.J., Kamali Kannangara G.S, Wilson M.A.; (2003), Ind. Eng. Chem. Res., 42, 6673-6681.

19. Whelan T.J., Wilson M.A., Kamali Kannangara G.S.; (2002). Australian Organic Geochemistry Conference, 77-78,

20. Susic M.; (1990), J. Chromatogr., 502, 443-444.

21. Xiao J.B., Chen X.Q., Jiang X.Y., Wu S.D.; (2006), Ann. di Chim., 96, 347-354. 
22. Baker A.R., Greenaway A.M., Ingram C.W.; (1995), Talanta, 42, 13551360.

23. Smeulders D.E., Wilson M.A., Armstrong L.; (2001), Ind. Eng. Chem. Res., 40, 2243-2251.

24. Wilson. M.A, Ellis A.V., Lee G.S.H., Rose H.R., Lu X.Q., Young B.R.; (1999), Ind. Eng. Chem. Res. 38, 4663-4674
25. Mori M., Taoda H., Itabashi H., Ikedo M., Tanaka K.; (2006), Acta Chromatographica, 16, 28-37

26. Vermeiren K.; (2005), J. Chromatogr. A., 1085, 66-73.

27. Chen Y., Ye M., Cui H., Wu F., Zhu Y., Fritz J.S.; (2006), J. Chromatogr. A., 1118, 155-159.

28. Chen Y., Jing L., Li X., Zhu Y.; (2006), J. Chromatogr. A., 1118, 3-1 